\title{
Perancangan Sistem Aplikasi Penjualan Paket Wisata Pulau Seribu Berbasis Java Dengan Metode Scrum (Studi Kasus PT. Abarter Global Indonesia)
}

\author{
Irfan Fakhruddin ${ }^{1 *}$, Nofita Rismawati ${ }^{2}$, dan Rini Sriyanti ${ }^{3}$ \\ Program Studi Teknik Informatika - Universitas Indraprasta PGRI \\ TB Simatupang, Jakarta 12530 \\ Corresponding author's e-mail: irfanfakhruddin29@gmail.com¹, novi.9001@gmail.com², \\ abib.arsyilla@yahoo.com ${ }^{3}$
}

\begin{abstract}
Abstrak - Tujuan penelitian ini untuk mempermudah customer dalam melakukan pemesanan paket wisata pulau seribu, mempermudah customer dalam mendapatkan informasi tiket dan jadwal keberangkatan dan mempermudah travel agent dan customer dalam mengelola data penumpang dan data pemesanan tiket. Sebelumnya PT Abarter Global Indonesia masih menggunakan metode manual untuk pelayanan penjualan paket wisata. Hal tersebut membuat pelayanan menjadi tidak efektif dan tidak efisien seperti pendataan customer yang masih ditulis dibuku dan antrean customer yang memakan waktu lama. Dalam menyelesaikan masalah tersebut penulis menggunakan Metode Scrum pada sistem terkomputerisasi menggunakan Java Netbeans. Hasil dari penelitian yang dilakukan di PT Abarter Global Indonesia, aplikasi yang dikerjakan dapat mempermudah admin dalam proses pemesanan paket wisata pada PT Abarter Global Indonesia dan membuat transaksi menjadi lebih mudah, cepat dan efisien.
\end{abstract}

Kata kunci: Perancangan, Penjualan Paket Wisata, Metode Scrum, Java, UML

Abstract - The purpose of this research is to make it easier for customers to order pulau seribu tour packages, make it easier for customers to get ticket information and departure schedules and make it easier for travel agents and customers to manage passanger data and ticket booking data. Previously PT Abarter Global Indonesia still users the manual method for selling their tour package. This makes services ineffective and inefficient, such as customer data collection that is still written in books and customer queques that take a long time. In solving this problem the author uses the scrum method on a computerized system using Java Netbeans. The results of research conducted at PT Abarter Global Indonesia, the application that is done can make it easier for admins in the process of ordering tour packages at PT Abarter Global Indonesia and make transactions easier, faster and more efficent.

Keywords : Designing, Tourist Package Sales, Scrum Method, Java, UML

\section{Pendahuluan}

Dengan meningkatnya teknologi, perusahaan dituntut untuk merencanakan strategi pemasaran untuk mengikuti perkembangan dunia digital[1]. Salah satu bisnis yang sangat membutuhkan penggunaan teknologi adalah di bidang pariwisata, salah satunya PT. Abarter Global Indonesia. PT. Abarter Global Indonesia sendiri bergerak dalam bidang Penjualan Paket Wisata Pulau Seribu.

Saat ini PT. Abarter Global Indonesia masih menggunakan metode manual untuk pelayanan penjualan paket wisata mereka. Hal tersebut membuat pelayanan menjadi tidak efektif dan tidak efisien, seperti pendataan customer yang masih ditulis di buku dan antrean customer yang memakan waktu lama. Berdasarkan kebutuhan di atas maka PT. Abarter Global Indonesia membutuhkan suatu sistem informasi yang dapat mendukung pengolahan data pemesanan secara cepat, akurat dan tepat serta dapat memberikan kemudahan bagi admin dalam hal pelayanan.

Penelitian dibatasi pada masalah pembuatan aplikasi yang dapat diakses oleh admin, pimpinan perusahaan dan agen di PT. Abarter Global Indonesia serta aplikasi pemesanan paket wisata pulau seribu yang berisikan fitur-fitur untuk melihat data penumpang perjalanan dan laporan. Perumusan masalah dalam penelitian ini adalah bagaimana penerapan metode scrum dalam pemesanan tiket pada PT Abarter Global Indonesia dapat dikelola menggunakan aplikasi ini sehingga dapat dilakukan dengan optimal. Selain itu, juga bagaimana membantu admin dalam mengelola pemesanan tiket agar efektif dan efisien serta cara membangun dan mengimplementasikan system aplikasi pemesanan tiket.

Penelitian ini bertujuan membuat aplikasi yang dapat mempermudah customer dalam mendapatkan informasi pemesanan paket, pemesanan tiket dan jadwal keberangkatan. Pembuatan aplikasi juga dilakukan untuk mempermudah travel agent dan costumer dalam mengelola data penumpang dan pemesanan tiket. 


\section{Tinjauan Pustaka}

\subsection{Landasan Teori}

Andri Kristanto (2013:61) "Perancangan sistem adalah suatu fase dimana diperlukan suatu keahlian perancangan untuk elemen-elemen komputer yang akan menggunakan sistem, yaitu pemilihan peralatan dan program komputer untuk sistem yang baru[1][9].

Menurut Riyowati \& Fadlilah (2019), menyatakan aplikasi merupakan program yang siap dipakai dan digunakan untuk menjalankan perintah user dengan tujuan untuk mendapatkan hasil yang tepat dan akurat sesuai dengan tujuan dari pembuatan aplikasi tersebut[2][10].

Menurut Thamrin Abdullah dan Francis Tantri $(2016,3)$ Penjualan adalah bagian dari promosi dan promosi adalah salah satu bagian dari keseluruhan sistem pemasaran[3].

Menurut Kodhyat dalam Kurniansah (2014:28) pariwisata adalah perjalanan dari satu tempat ketempat lain bersifat sementara, dilakukan perorangan atau kelompok, sebagai usaha mencari keseimbangan atau keserasian dan kebahagiaan dengan lingkungan dalam dimensi social budaya, alam dan ilmu[4].

Scrum menurut (Wahyudi, 2018) adalah salah satu metode pengembangan aplikasi dengan pengimplementasian proses Agile Development. Scrum mempunyai perbedaan yang signifikan dikarenakan produk yang dihasilkan akan menyesuaikan dengan lingkungan seiring waktu proses pengembangan berlalu[5].

Menurut Rosa Dan Shalahuddin (2015:13), menyatakan bahwa UML (Unified Modelling Language) adalah salah satu standard bahasa yang banyak digunakan didunia industri untuk mendefinisikan requirement, membuat analisis dan desain, serta menggambarkan arsitektur dalam pemrograman berorientasi objek [6][11].

Menurut Nofriardi (2015:1) "bahasa pemrograman java merupakan salah satu dari sekian banyak bahasa pemrograman yang dapat dijalankan di berbagai sistem operasi termasuk telepon genggam[7]".

\subsection{Penelitian Yang Relevan}

Penelitian oleh Ashary Gusti Saputra yang berjudul " Penerapan E-Travelling Menggunakan Model Fast Pada Babeltravellers" bertujuan untuk merancang dan membangun suatu perangkat lunak pemesanan tiket yang dapat membantu meningkatkan pelayanan dan kinerja operator dalam melayani pemesanan tiket berbasis aplikasi desktop. Angga Dani Eka Saputra at.al melakukan pengembangan sistem informasi pemesanan paket wisata berbasis web agar dapat meningkatkan penjualan secara online melalui website dan menunjang kegiatan promo dan menarik perhatian calon konsumen baru.

\section{Metode Penelitian}

Penelitian dilakukan pada PT Abarter Global Indonesia dari bulan September 2021 sampai Februari 2022. Tempat penelitian di Jalan Raya Kampung Sawah RT 5 Rw 1 No 120, Kelurahan Jatimurni, Kecamatan Pondok Melati, Bekasi 17431.

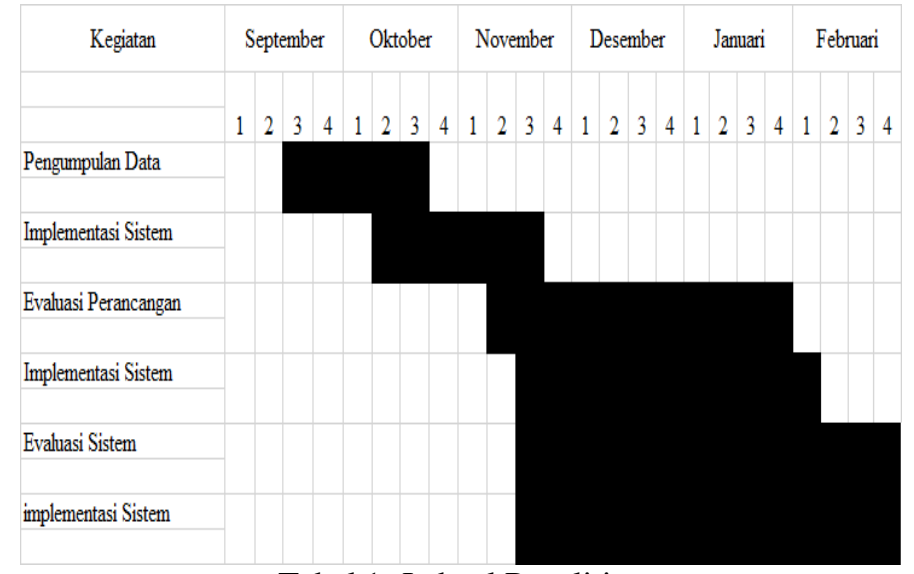

Tabel 1. Jadwal Penelitian

Metode penelitian yang digunakan oleh penulis dalam tugas akhir ini adalah metode Scrum. Metode Scrum menurut (Forda et al., 2019) merupakan sebuah metode yang menggunakan iterasi dan kerangka tambahan pada sebuah project yang akan dikembangkan. Siklus-Siklus kegiatan atau pekerjaan pada Scrum dimana aplikasi tersebut akan dikembangkan disebut dengan Sprint dimana kegiatan Sprint dilakukan dalam jangka waktu 1 bulan atau artinya kegiatan Sprint dilakukan tanpa berhenti[8]. 
3.1 Use Case Diagram

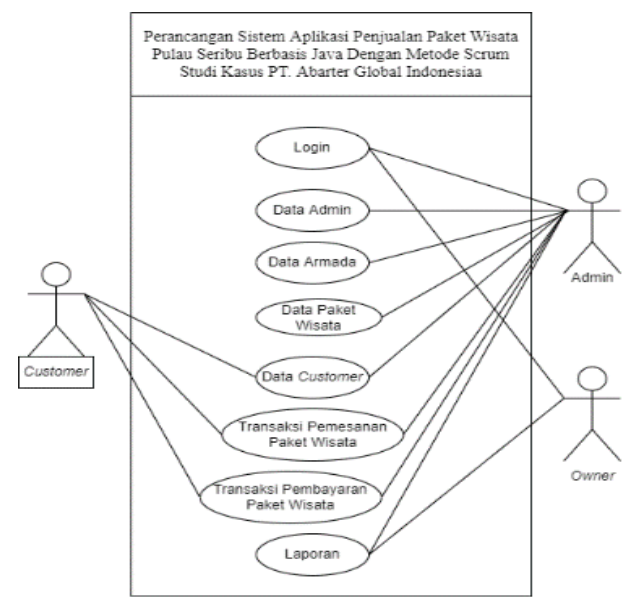

Gambar 1. Use Case Diagram

\subsection{Activity Diagram}

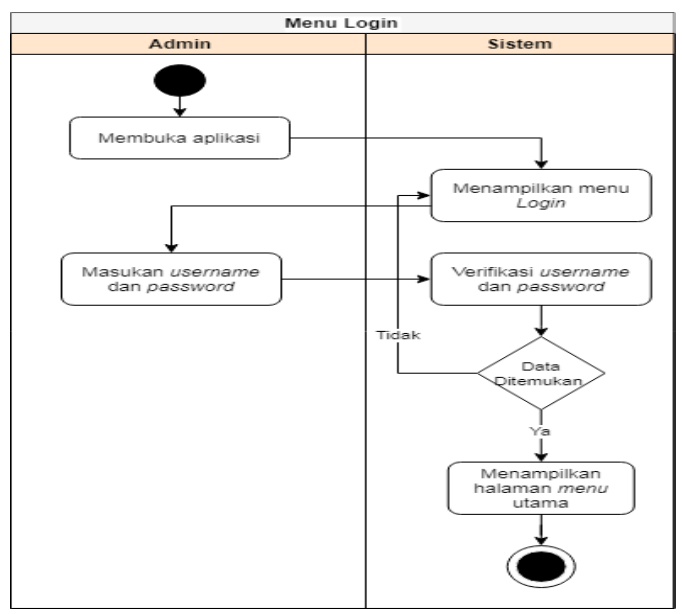

Gambar 2. Activity Diagram Login

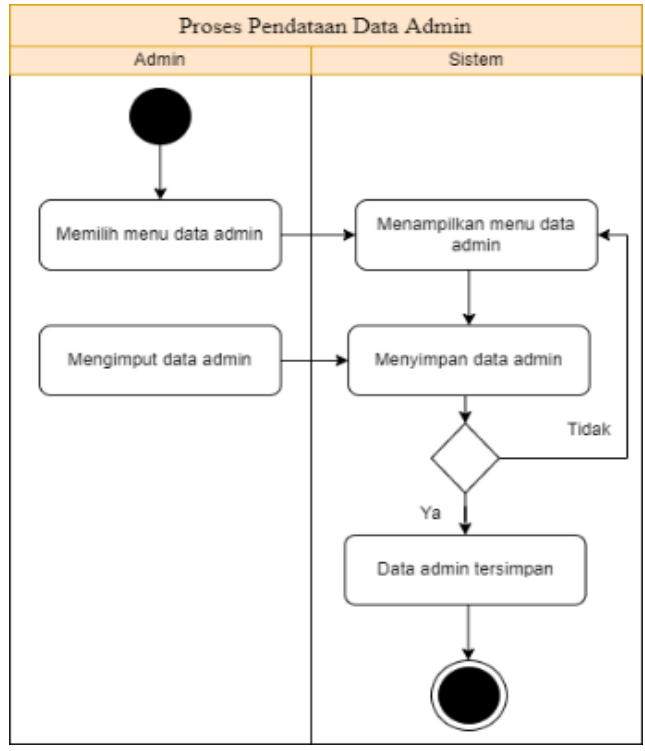

Gambar 3. Activity Diagram Proses Pendataan Data Admin 


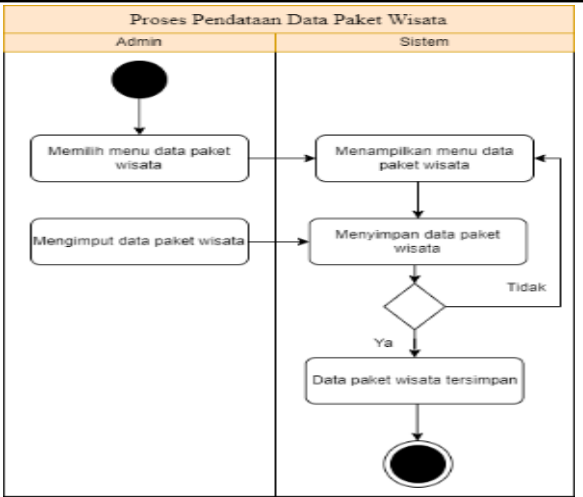

Gambar 4. Activity Diagram Mengelola Data Paket Wisata

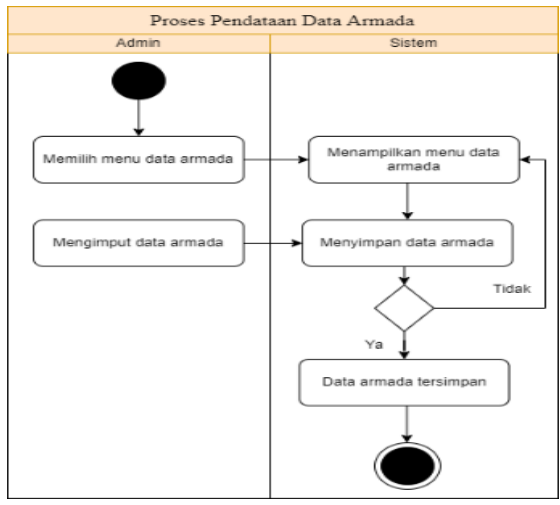

Gambar 5. Activity Diagram Mengelola Data Armada

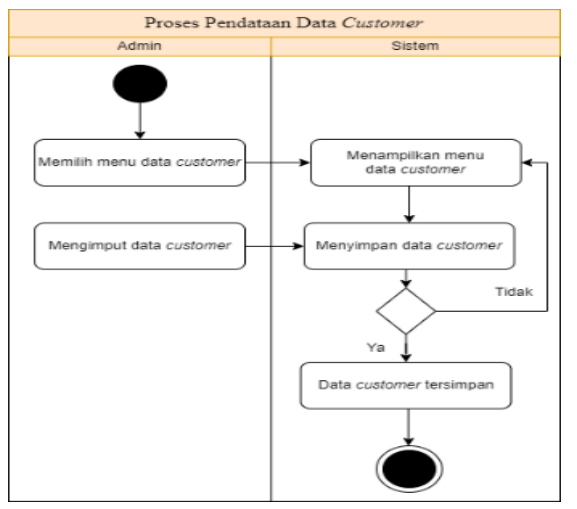

Gambar 6. Activity Diagram Mengelola Data Customer

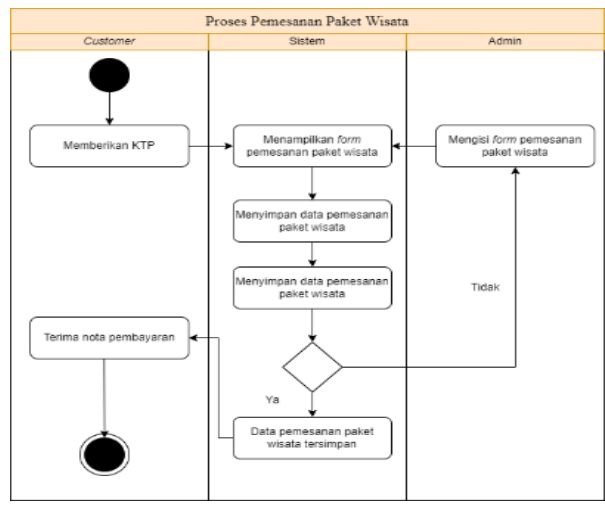

Gambar 7. Activity Diagram Mengelola Data Pemesanan Paket Wisata 


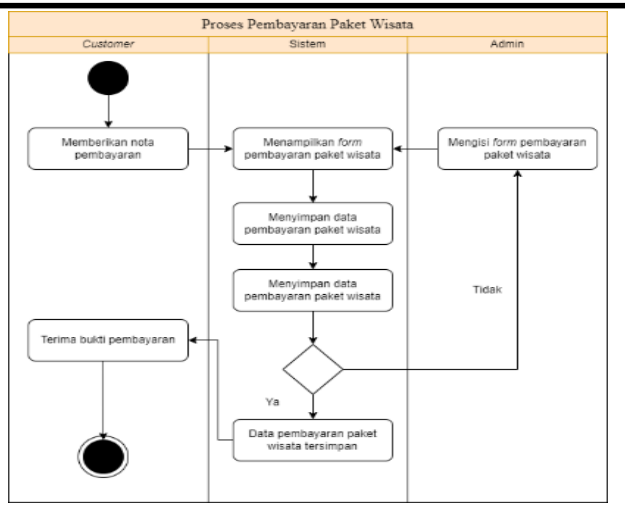

Gambar 8. Activity Diagram Mengelola Data Pembayaran Paket Wisata

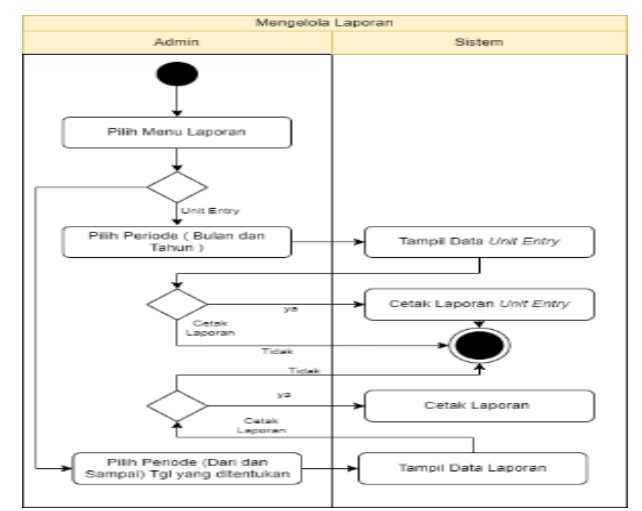

Gambar 9. Activity Diagram Mengelola Data Laporan

\subsection{Entity Relationship Diagram}

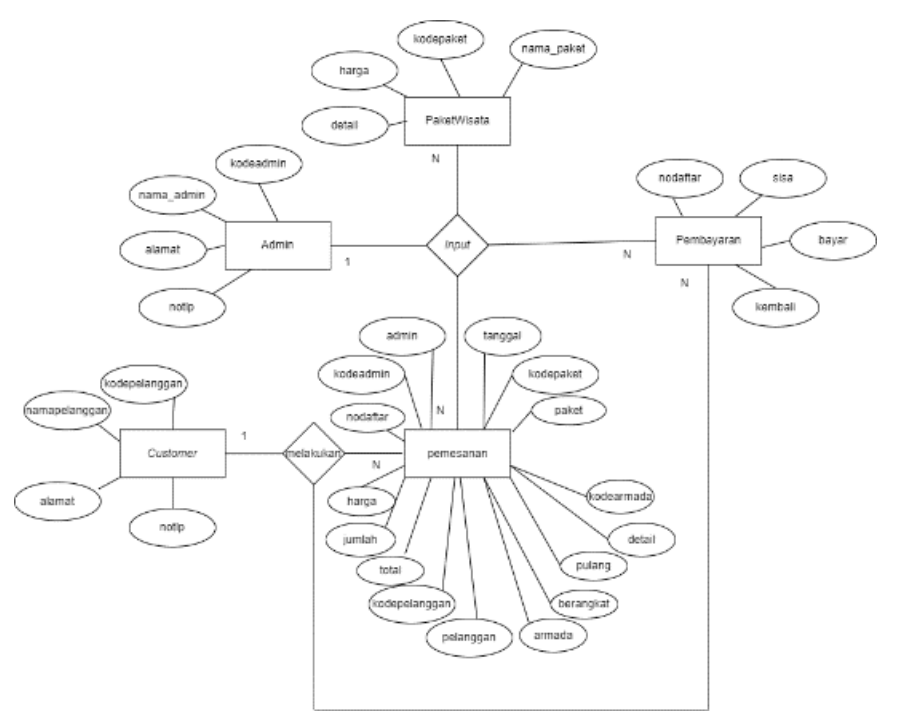

Gambar 10. Entity Relationship Diagram 


\section{Hasil Penelitian}

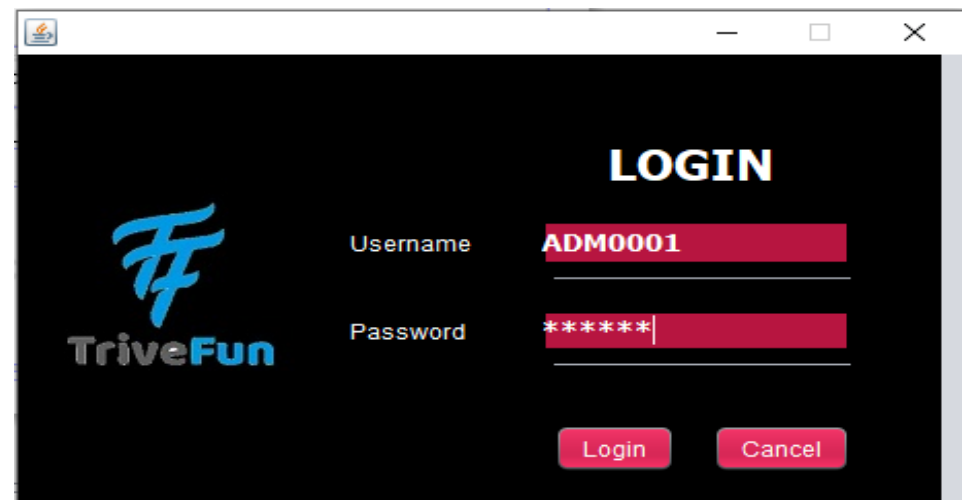

Gambar 11. Tampilan Layar Halaman Login

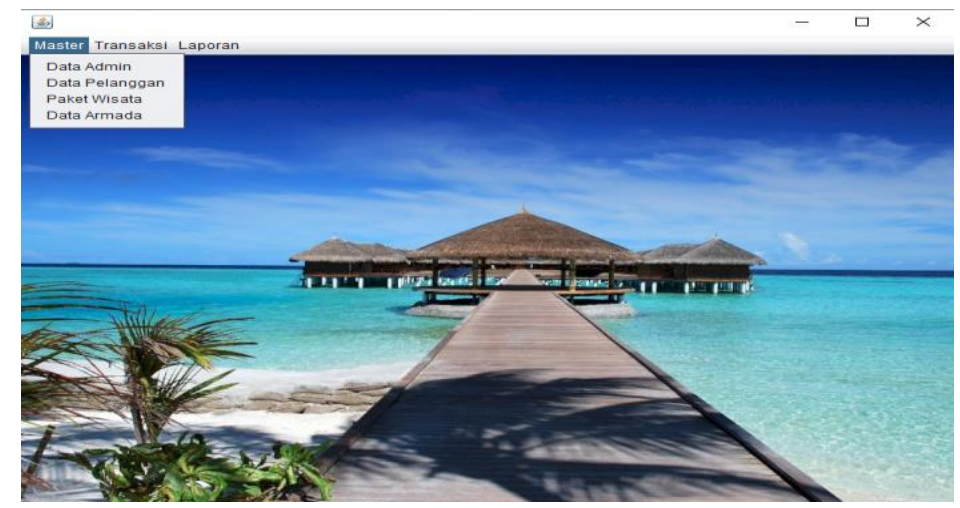

Gambar 12. Halaman Form Menu Utama

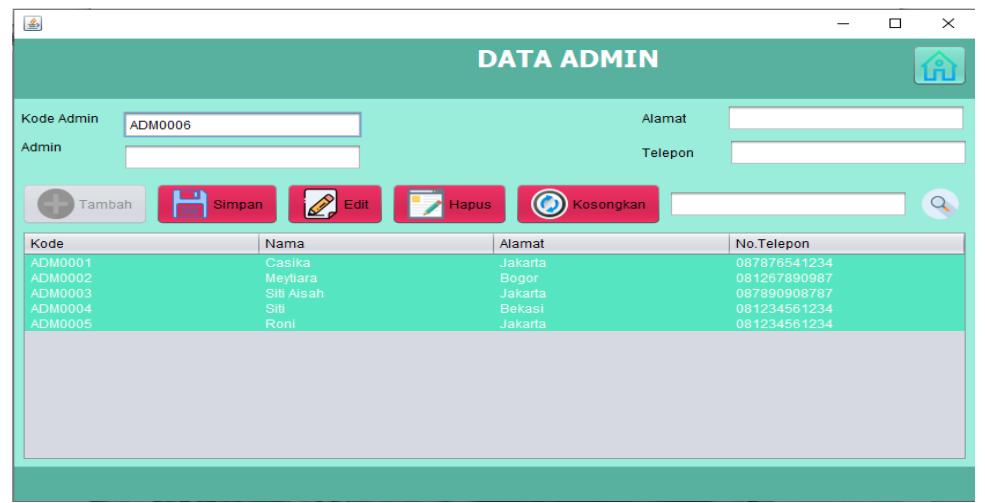

Gambar 13. Halaman Form Data Admin

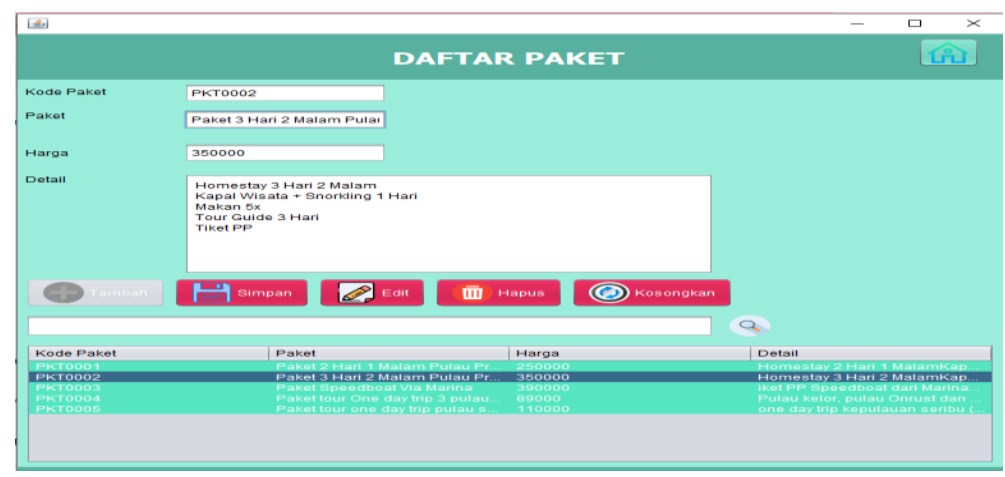

Gambar 14. Halaman Form Data Paket Wisata 


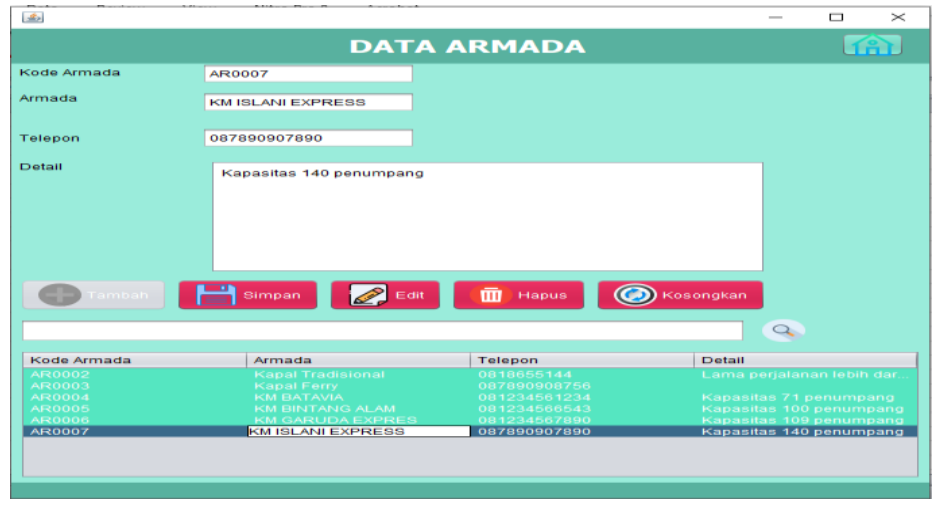

Gambar 15. Halaman Form Data Armada

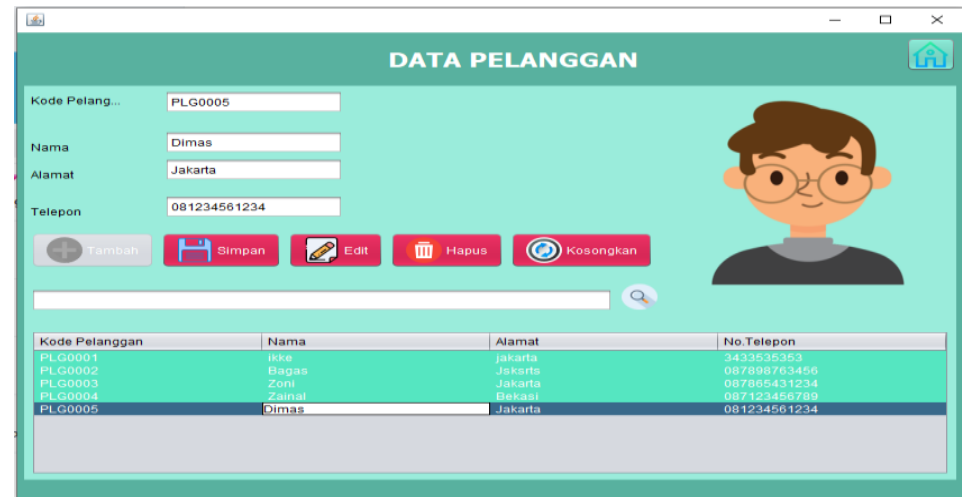

Gambar 16. Halaman Form Data Customer

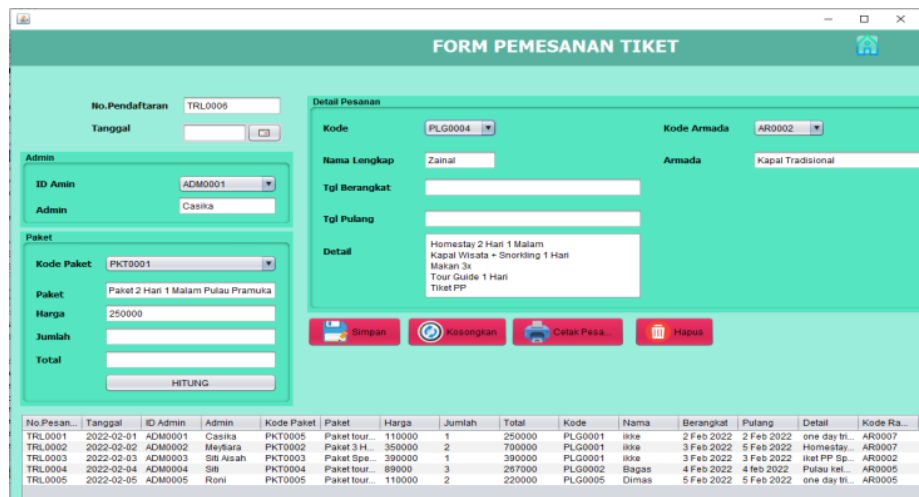

Gambar 17. Halaman Form Pemesanan Paket Wisata

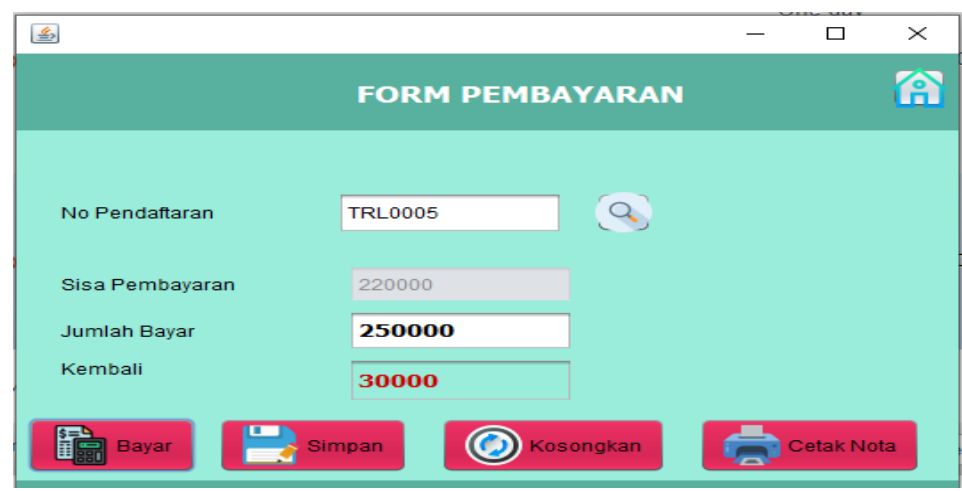

Gambar 18. Halaman Form Pembayaran Paket Wisata 


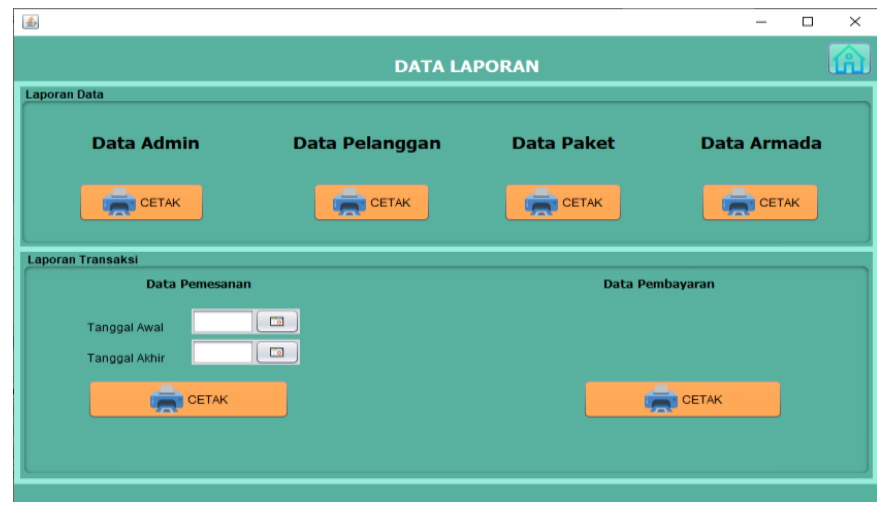

Gambar 19. Halaman Form Data Laporan

\section{Kesimpulan}

Berdasarkan hasil dari penelitian penulis bahwa perancangan sistem aplikasi penjualan paket wisata pulau seribu dengan menggunakan metode scrum pada PT. Abarter Global Indonesia telah berhasil dibuat, maka menghasilkankriteria aplikasi yaitu master data, pemesanan paket wisata, pembayaran paket wisata, dan laporan. Dari hasil uji coba yang telah di lakukan pada perusahaan maka kesimpulan yang didapat pada perancangan sistem aplikasi penjualan paket wisata pulau seribu menjadi lebih mudah dilakukan, cepat, dan efisien.

\section{Daftar Pustaka}

[1] Abdurahman, H., \& Riswaya, A. R. (2014). Aplikasi pinjaman pembayaran secara kredit pada bank yudha bhakti. Jurnal Computech \& Bisnis, 8(2), 61-69.

[2] Abdussalaam, F., \& Saputra, S. A. (2018). Perancangan Sistem Informasi Complaint Management Dengan Metode Rad Menggunakan Framework Laravel. Jurnal E-Komtek (Elektro-Komputer-Teknik), 2(2), 54-68.

[3] Abimanyu, D. S. (2020). Aplikasi Persediaan Dan Penjualan Pada Toko Tani Mandiri Berbasis Website. Politeknik Negeri Sriwijaya.

[4] Daya, P. (2021). Pengembangan Fitur Push Notification Pada Aplikasi Igracias Mobile Menggunakan Metode Scrum. Institut Teknologi Telkom Purwokerto.

[5] Dellarosawati, M. (2020). Riset Teknologi Finansial Untuk Umkm Dalam Menunjang Laporan Keuangan. Methosika: Jurnal Akuntansi Dan Keuangan Methodist, 3(1), 33-38.

[6] Fakhrurrozi, M. (2019). Analisis Strategi Promosi Dalam Pengembangan Pariwisata (Studi Kasus pada Ranu Klakah di Kecamatan Klakah Kabupaten Lumajang).

[7] Fikri, I. M. (2018). Aktivitas Penjualan Mobil Baru Kategori Low Cost Green Car pada PT. Intercom Mobilindo Padang. Universitas Andalas.

[8] Fridayanthie, E. W., \& Charter, J. (2016). Rancang Bangun Sistem Informasi Simpan Pinjam Karyawan Menggunakan Metode Object Oriented Programming (Studi Kasus: PT. Arta Buana Sakti Tangerang). Techno Nusa Mandiri: Journal of Computing and Information Technology, 13(2), 149-156.

[9] S. Susmanto, M. Munawir, E. Erdiwansyah, Z. Zulfan, and D. Setiyadi, "Perancangan E-Voting pemilihan Kepala Desa untuk Transparansi Informasi di Kecamatan Lueng Bata Kota Banda Aceh," J. Serambi Eng., vol. 7, no. 1, 2022.

[10] D. Satria, S. Yana, E. Yusibani, and S. Syahreza, "Zulfan, 'Implementation of the SMS gateway in the flood early warning information system for village warning and community information," Int. J. Eng. Adv. Technol, vol. 8, no. 6, pp. 4005-4009, 2019.

[11] R. Islamadina, S. Mustafa, and S. Muklis, "Sistem Informasi Monitoring Kehadiran Siswa dalam Pengawasan Orang Tua pada Sekolah Menengah Kejuruan (SMK) Negeri 4 Banda Aceh," J. Nas. Komputasi dan Teknol. Inf., vol. 4, no. 3, pp. 227-238, 2021. 